\title{
Cancer beliefs and cancer screening behaviors among low income Chinese immigrants - Implications for culturally relevant interventions
}

\author{
Kenny Kwong * \\ Touro College Graduate School of Social Work, United States
}

Received: March 2, 2016

DOI: $10.5430 /$ jnep.v6n10p130

\author{
Accepted: May 29, 2016 \\ Online Published: June 15, 2016 \\ URL: http://dx.doi.org/10.5430/jnep.v6n10p130
}

\begin{abstract}
Objective: To effectively plan and provide culturally appropriate cancer education and screening services for low income Chinese immigrants, accurate disaggregated data are very much needed in understanding their cultural beliefs, attitudes, and practices toward cancer screening and education. This study explored the views of medically underserved Chinese immigrants in the United States and assessed their beliefs and attitudes toward the cause and prevention of breast, cervical, and prostate cancer, and their cancers screening behaviors.

Methods: Guided by both the Explanatory Model Interview Catalogue and the Health Belief Model, an exploratory research methodology was used. Narrative data from in-depth interviews and focus groups were studied qualitatively. The data analytical procedure was based on immersion in the narrative data, writing memos, sorting data into codes and categories, and comparing themes across interviews. Thirty-nine low-income Chinese men and women participated in 14 in-depth interviews and 4 focus groups.

Results: Findings provided evidence of strong influence of Chinese culture on beliefs and attitudes toward cancer, as well as perceptions regarding the cause, risk, susceptibility to, and seriousness of cancer. Participants reported both positive and negative perception toward cancer. Common misconceptions about the causes of cancer included: excessive sexual activities, having a certain blood type, cancer being "contagious", and women ignoring their reproductive or natural functions by using birth control or not breastfeeding.

Conclusions: The study highlights the importance of cultural appropriateness and relevancy in the development and implementation of cancer promotion and cancer screening interventions for the Chinese immigrant population.
\end{abstract}

Key Words: Chinese immigrants, Beliefs, Cancer screening, Qualitative approach

\section{INTRODUCTION}

Breast cancer is the leading cause of cancer and is among the top 3 cancer causes of death for Chinese American women. ${ }^{[1]}$ Prostate cancer is one of the top five causes of cancer mortality among Asian American and Pacific Islander (AAPI) males. $^{[2]}$ Specific data of cancer morbidity and mortality rates among Chinese American men is scarce. AAPI men have the lowest incidence and mortality rates of prostate cancer. However, they are more likely to be diagnosed with advanced stage prostate cancer than other racial and ethnic

\footnotetext{
*Correspondence: Kenny Kwong, Associate Professor; Email: kam.kwong@ touro.edu; Address: Touro College Graduate School of Social Work, United States.
} 
groups. ${ }^{[3,4]}$ Survival rates after diagnosis of early-stage cervical carcinoma are also found lower in Chinese women compared to other Asian sub-groups and non-Asian populations, including Filipino, Japanese, and non-Hispanic white women in the United States. ${ }^{[5]}$

The American Cancer Society publishes recommendations and guidelines for the early detection of breast, cervical, and prostate cancers. ${ }^{[6-8]}$ Whereas screening guidelines are shown to be effective in lowering the risk of developing breast and cervical cancer, there remain significant uncertainties regarding the risk and benefits of prostate cancer screening. ${ }^{[9]}$ Recent research studies assessed the adherence to breast and cervical cancer screenings among Chinese American women and found very low screening rates among these women when compared to Whites. ${ }^{[10-13]}$ Despite recent significant effort to promote cancer screenings in local communities, the overall screening rate of Chinese American women is still below the national average and far behind the objectives of Healthy People 2010. ${ }^{[10]}$ AAPI men are also least likely to report ever having a prostate cancer screening test than other racial and ethnic groups. ${ }^{[3,4]}$ All these studies found that factors such as language, level of English proficiency, economic barriers, social constraints, low or limited knowledge of cancer and cancer screening guidelines, and community perceptions and biases toward cancer diagnoses all contributed to the lack of participation in cancer screening services among Chinese American populations.

The Chinese American population in New York City is growing rapidly with an increase of 33\% from 357,243 in 2000 to 474,783 in 2010 , with the majority being foreign born. ${ }^{[14]}$ The Chinese American population is not only increasing in number, but is also becoming more heterogeneous in its socio-demographic characteristics such as income, education, social status, immigration status, and immigration background (rural versus urban). It is in itself a diverse group with differences in spoken dialects, levels of acculturation, as well as beliefs and practices toward health, illness, and treatment. To effectively plan and provide culturally appropriate cancer education and screening services, accurate disaggregated data for the Chinese immigrant population are very much needed in understanding their cultural beliefs, attitudes, and practices toward cancer screening and education.

Cultural beliefs, attitudes, and life experiences affect an immigrant's reaction to cancer, body pain and discomforts, and various preventive health practices and disease management. ${ }^{[15]}$ Several studies explored the perception regarding risk, vulnerability, susceptibility to, and seriousness of cancer among Asian American women. ${ }^{[16-18]}$ These studies found that Asian American women believed they had a lower risk

Published by Sciedu Press of breast and cervical cancer than American women and therefore associated the need of preventive screening activity with American women rather than with themselves. Cancer has a very negative connotation in the Chinese American community. ${ }^{[19]}$ Chinese American women tend to underestimate their risk of getting breast cancer and undervalue the importance of mammography. ${ }^{[20]}$ Although Chinese immigrant women experience similar psychosocial barriers as other minority women in the U.S., they also share culturally related barriers such as feeling shame, stigma, and isolation for not sharing diagnosis with anyone, and beliefs that Eastern medicine is milder than Western medicine in treating or preventing illness. ${ }^{[21]}$ The fear that cancer is fatal prevails among Chinese American women ${ }^{[11,19,22]}$ and among Asian American men. ${ }^{[23,24]}$ Some Chinese believe cancer is contagious $^{[25,26]}$ and severe. ${ }^{[13]}$ For many Chinese patients, the initial immediate reaction when discovering cancer is one of shock, disbelief, disregard, and belief of breast cancer as an indication of bad luck. ${ }^{[25,27]}$ Others believe breast cancer is a curse and that they can avoid breast cancer by thinking positively, adopting a healthy diet, and having a balanced life. ${ }^{[22,25]}$ All these barriers may affect adherence to cancer screening and treatment in the Chinese American community.

Modesty as a personal factor inhibiting Chinese women from obtaining pap smears is also cited as a barrier. ${ }^{[18]}$ Because of the conservative cultural attitudes toward gender-related health topics and exposing one's body, some AAPI men may feel very uncomfortable discussing the need for prostate cancer screening with female healthcare providers. ${ }^{[24]}$ For AAPI unmarried women, because of the cultural expectation that women should not engage in sexual activity before marriage, and since cervical cancer screening is related to sexuality, both healthcare providers and unmarried sexually active women may risk considerable embarrassment when discussing the need for a Pap smear test. ${ }^{[28]}$

The holistic concept is an important idea in traditional Chinese culture that affects the preventive health and disease management behaviors of Chinese individuals. ${ }^{[29]}$ Taoism promotes the belief that nature has the ultimate authority over the course of one's life and existence ${ }^{[30]}$ and that one is not in complete control of nature nor in one's destiny. The Taoist belief that health is a state of spiritual and physical harmony with nature ${ }^{[29]}$ is contrary to the Western belief that health is determined by one's efforts. Prior research suggests that traditional Chinese values like fatalism and the holistic balance of Yin (cold) and Yang (hot) prevented some Chinese individuals from seeking Western medical care and created misconceptions of illness and cancer screening. ${ }^{[31]}$ For them, Western diagnostic procedures are not used for 
screening purposes but for a health problem only. Therefore, they cannot understand why so many diagnostic tests are necessary. ${ }^{[29]}$ A Chinese immigrant who has no experience with preventive care may not comprehend the concept of screening for a disease that she or he probably does not have.

In summary, healthcare providers need to recognize the ramification of these cultural beliefs and attitudes on cancer screening behaviors among Chinese immigrant populations and their implications on early detection and screening activities. Little is known specifically about cultural beliefs, attitudes, and practices of low income Chinese immigrants toward cancer screening and education. The lack of studies and data on cancer education and screening among this medically underserved population is a major constraint for health organizations to effectively plan and provide culturally appropriate cancer screening services and health education for them.

\section{MethodS}

\subsection{Study purpose and questions}

The purpose of this study was to explore the views of cancer among Chinese immigrants and assess their beliefs and attitudes toward the causes and prevention of these cancer sites, and their cancer screening behaviors. Semi-structured openended questions were used to assess the cultural attitudes and beliefs of Chinese immigrants on the causes of cancer, their perceived susceptibility to cancer, and how their attitudes and beliefs affected their cancer screening behavior. To elicit and encourage more participant responses, follow-up questions were also used. Participants were asked what came to their mind when they heard about "cancer" and what caused cancer. They were then asked if they considered themselves as being at risk for cancer. Finally they were asked if they considered cancer as a serious disease and if they believed that thinking or finding out about cancer could provoke the onset of cancer. Before the interview, participants were asked to provide their own background information such as age, marital status, employment status, level of education, and level of English fluency. All focus groups and individual interviews were conducted in the participants' native dialect. Each individual interview lasted for about an hour. Each focus group interview lasted for about two hours. The study was approved by the Human Research Protection Program of Hunter College.

\subsection{Conceptual framework and study design}

This study used a qualitative exploratory approach to explore Chinese participants' cancer beliefs and experiences and to identify themes and concepts that emerged from interview data. ${ }^{[32]}$ Based on the thematic analysis approach, codes, categories, and themes were developed inductively from focus group and interview data. ${ }^{[33]}$ The development of the interview topics was guided by both the Explanatory Model Interview Catalogue (EMIC) ${ }^{[34]}$ and the Health Belief Model (HBM). ${ }^{[35]}$ The EMIC ${ }^{[34]}$ was adapted to study cancer belief of Chinese immigrants, their perceived causes of cancer, and their practice toward cancer screening. The HBM is a commonly used health promotion framework emphasizing the role of health beliefs in the study of health behavior change. ${ }^{[35]}$ Key dimensions of this model include perceived susceptibility and perceived severity of disease, and perceived barriers to and benefits of carrying out a recommended preventive health activity. Both individual interviews and focus groups are common instruments of data collection in qualitative research. One-on-one interviewing is an effective approach for information gathering with ethnic minority and fragile individuals who may feel intimated if they have to articulate their ideas in a group setting. Focus groups, on the other hand, are more effective when participants are relatively verbal and articulate, and may yield a wide range of perspectives that may not be easily obtained through other methods. Synergism created from group interaction may also stimulate new ideas and high levels of energy in discussion.

\subsection{Study sample}

This study targeted Chinese immigrant men and women who participated in cancer screening and information services in New York City. Thirty-nine participants were recruited from the client population of a community health center that serves more than 30,000 Chinese adults aged over 18, the majority of whom live at or below the federal poverty line. Recruitment flyers were posted at various sites of the health center's bulletin boards as well as made available at the reception desk and patient waiting areas. Fourteen in-depth individual interviews and 4 focus groups were completed. Of these participants, five participated both in individual and focus group interviews. The sampling design was meant to include the breadth of perspectives shared by these participants rather than aiming at generalizing to the larger Chinese immigrant population. Participants who were diverse in their demographic characteristics such as age, gender, preferred spoken dialect, education, and length of stay in the U.S. were included to capture variations in their cancer beliefs and practices. Participants who had the same gender and spoke the same Chinese dialect (Mandarin or Cantonese) were placed in the same focus group to facilitate communication of personal beliefs and perspectives. Two focus groups were conducted with Chinese women who had received cervical and breast cancer screening services. Another two groups were completed with Chinese men who received prostate 
cancer screening services.

Table 1 summarizes the background characteristics of 39 participants. Eighteen participants were female and 21 were male. The average age was 56.8 years old $(\mathrm{SD}=14.9)$. All participants were immigrant Chinese and their average number of years living in the U.S. was 15.7 years $(\mathrm{SD}=$ 11.9). Most participants were married (74.4\%). Approximately $47 \%$ were employed. The majority $(73.5 \%)$ reported their total annual income to be below $\$ 20,000$. The majority $(69 \%)$ had received a high school education or less, and spoke English poorly or could not speak English at all (55\%).

Table 1. Demographic characteristics of participants $(\mathrm{N}=$ 39)

\begin{tabular}{|c|c|c|c|}
\hline Variable & & & \\
\hline & Mean & S.D. & Range \\
\hline Age (years) & 56.8 & 14.9 & $25-78$ \\
\hline \multirow[t]{2}{*}{ Years in United States } & 15.7 & 11.9 & $1-53$ \\
\hline & Number & $\%$ & \\
\hline \multicolumn{4}{|l|}{ Gender } \\
\hline Male & 21 & 53.8 & \\
\hline Female & 18 & 46.2 & \\
\hline \multicolumn{4}{|l|}{ Race } \\
\hline Asian/Chinese & 39 & 100 & \\
\hline \multicolumn{4}{|l|}{ Marital Status } \\
\hline Married & 29 & 74.4 & \\
\hline Divorced & 4 & 10.3 & \\
\hline Widowed & 3 & 7.7 & \\
\hline \multicolumn{4}{|l|}{ Education } \\
\hline None/Elementary & 8 & 20.5 & \\
\hline Junior High & 8 & 20.5 & \\
\hline High School Graduate & 11 & 28.2 & \\
\hline College Graduate & 12 & 30.8 & \\
\hline \multicolumn{4}{|l|}{ Employment Status } \\
\hline Employed & 18 & 47.4 & \\
\hline Unemployed & 2 & 5.3 & \\
\hline Retired & 13 & 34.2 & \\
\hline \multicolumn{4}{|l|}{ Annual Income } \\
\hline$<\$ 20,000$ & 25 & 73.5 & \\
\hline$\$ 20,000$ or more & 9 & 26.5 & \\
\hline \multicolumn{4}{|l|}{ English Fluency } \\
\hline Well & 3 & 7.9 & \\
\hline Some & 14 & 36.8 & \\
\hline Poor & 11 & 28.9 & \\
\hline Not at All & 10 & 26.3 & \\
\hline
\end{tabular}

\subsection{Data analysis procedure}

Narrative data from individual and focus group interviews were studied qualitatively using technical steps based on the thematic analysis approach. ${ }^{[33]}$ The data analytical procedure was based on immersion in the narrative data, writing memos, sorting data into codes and categories, and comparing themes across interviews. The study used a qualitative analysis software program, ATLAS.ti, to help code and organize the data. ${ }^{[36]}$ Several data analytical steps were used. All interview narratives were transcribed into English by qualified bilingual healthcare professionals. Open coding was used to scrutinize interview data's body of words, phrases, and sentences. A tentative list of codes was created to code and classify the interview data. ${ }^{[32]}$ All narrative data, codes, quotations, and themes were analyzed systematically and constantly to identify connections between them. Both "self-reflective memos" and "analytical memos" including the researcher's own understanding and insights on the data were written. ${ }^{[37]}$ All these procedures were used to make the emerging themes and concepts denser. ${ }^{[32]}$

The researcher took additional steps to enhance credibility and trustworthiness of study data. ${ }^{[38]}$ A co-facilitator in each focus group interview took detailed notes on group dynamics and participant interactions to capture the non-verbal, sequential nature of group interaction and assess the possible effects of group interaction on participant responses. All group dynamics, interactions, agreements and disagreements that influenced participant responses were coded and analyzed. To enhance the accuracy of interpretations, a peer debriefing session among interviewers and the researcher was held immediately following each focus group interview. The researcher checked for the representativeness of key findings as well as quotations that were used to illustrate the concepts and themes. In addition, the researcher also checked to assess if descriptions or explanations on the data were both complete and accurate.

\section{RESUlts}

\subsection{Positive perception toward cancer}

Table 2 summarizes the major themes regarding cultural views and beliefs of Chinese participants toward cancer and cancer screenings. When participants of this study were asked about whether they believed that thinking or finding out about cancer could induce the onset of cancer, surprisingly none of them shared this view. They disagreed that talking or thinking about cancer would itself bring bad luck or lead to cancer. Five participants reported that they were calm when they heard about cancer, and 6 felt that they had control over what they could do to cope with cancer and were psychologically prepared for it. For instance, a participant indicated that she cared about her health so much that she would do whatever she could to fight the disease, "I think being healthy and not being sick is very important because it affects me in many different ways... only when they (other people) have illness or when they feel sick, then they seek 
medical care. If they feel fine and do not have any symptoms, they will not make an appointment to check whether they have cancer or not... For me, if I know, then at least I can be psychologically prepared, which is better than, oh, I have cancer, what now? The latter would be very scary to me."

Table 2. Themes regarding views and beliefs of Chinese participants toward cancer and cancer screening

\begin{tabular}{l} 
Positive perception toward cancer \\
\hline Disagreed that talking or thinking about cancer would itself \\
bring back luck or lead to cancer. \\
Some affirmed that cancer screening was a preventive \\
measure.
\end{tabular}

Negative perception toward cancer

Considered cancer as a fatal disease and has no cure.

Expressed a sense of powerlessness toward cancer.

Reported feelings of shock, fear, and withdrawal when heard about cancer.

Felt anxious, were in denial, and avoided dealing with the diagnosis.

Perceived seriousness and susceptibility to cancer

Believed that cancer could progress quickly and drastically without much warning.

More female than male participants believed they were more susceptible to having cancer.

Because of inadequate knowledge many believe they were vulnerable to developing cancer.

Misconceptions, confusions, and incorrect information about the cause of cancer

Only a few recognized the role of genetics and unhealthy diet as risk factors.

Many attributed cancer related symptoms to uncontrolled sexual desire or excessive sexual activities.

Many held misconceptions about the cause of cancer: having a certain blood type, poor hygiene, cancer being “contagious”, and women ignoring their reproductive or natural functions by using birth control or not breastfeeding.

Some participants (8) affirmed that that cancer screening was a preventive measure. They considered cancer screening as a tool for early detection and treatment. As one participant put it, "For cancers such as breast or cervical cancer, treatment in general was very effective. Therefore, there is no need to be overly concerned or scared when we heard about being diagnosed with cancer. Early detection and treatment of cancer in its early stage was very important and effective. It would be a concern if cancer is diagnosed at a late stage." Another participant commented, "It is important to be informed about your condition and be diagnosed and treated in the early stage of the disease. Prompt treatment can take care of a lot of problems."

\subsection{Negative perception toward cancer}

While some participants were open to talk about cancer, others held a negative attitude toward cancer. Many participants associated cancer directly with death because unlike other chronic conditions, they did not know if cancer could be cured. As one participant said, "I know if diabetic patients follow their regimen - eat what they should eat, do not eat what they shouldn't eat - they won't die, they can be treated. But I don't know about cancer. I don't know if cancer can be cured." Several participants in this study expressed a sense of powerlessness toward cancer and were ready to accept their "fate". For instance, a participant in this study believed that there was no way to prevent cancer and felt powerless and had no control in her life, "Life is very unpredictable. Even though you have a lot of money, your life may end suddenly ... it is your fate that determines whether you have cancer or not." Another participant agreed, "For us [women], we can be cautious about many different things, but when it comes to cervical cancer, even you are attentive to your personal hygiene, you cannot avoid getting cancer."

The majority of participants in this study (18) felt scared when they first heard about cancer. One participant recalled, "I was scared when I felt something hard in my breast during self-examination. So I went to see a doctor again. She told me it was just the bone and there was nothing wrong... I was scared when I saw the doctor and I was afraid that the doctor didn't know whether it was a bone or something else... I couldn't tell from self-examination and I was afraid that the doctor couldn't tell from physical examination either. But the doctor said that area is not the breast. It was the chest bone... I'm getting old now and starting to have health problems. I am scared. A casual remark about me being sick would be enough to make me anxious.”

Several participants were sympathetic when they heard that someone has cancer. One participant recalled, "Why some have cancer and others do not... You will die and your life will cut short if the doctor can't cure you. I think it's a misfortune to die like this... I feel sad when I heard that someone had cancer. I was thinking that it would be such a pity for a person who was so young, looked so pretty to have cancer. I was thinking what she could have done differently... I hope that the doctor can cure her. I hope the doctor can provide good treatment for her and make her live longer, give her a chance to see more in this world."

The reason participants reacted with fear and disbelief to the diagnosis of cancer was because they knew very little about cancer and how cancer progressed. They participated in cancer screening and followed the doctor's instruction to get further testing. Because the doctor did not explain to them 
how cancer could be treated, they felt panicky and did not know what to do when diagnosed with cancer. A participant commented, "I have a friend who came here and had a Pap smear. As soon as she had cancer screening done, she was told that there was a lump in her cervix. She was told to see a doctor for further testing... But at the time when she heard that, she was scared. The doctor did not explain to her precisely how her illness would progress... She was told very little and she got so scared that she did not know what to do."

Some participants (6) felt very anxious when they heard about cancer. Others (3) were in denial or did not want to face it at all. Only 2 felt indifferent about cancer. For instance, a participant commented that many people did not want to accept the fact that they had cancer because they were afraid. Many knew what they needed to do but chose to ignore it or make excuses so that they did not have to deal with it.

I know that many seniors do not care about cancer. They said they were old. If they got cancer, they just died and it's not a big deal... so why bothered?! But I said, "what if you do not die immediately but have to suffer a long and painful death as a result of cancer?" They then said they were old and they would die anyway. They asked why they still had to watch their diet at their age. They said, "If you are only allowed to eat certain things but not other things, what pleasure is left in life?" (I4)

Not only would patients be in denial and avoid dealing with the diagnosis of cancer, family members might also withhold information from the patient rather than openly discuss screening results with the patient. For instance, one participant indicated that his children did not tell him what the tests were for until they received a negative result, "Last time when the doctor suspected that I had prostate cancer, my children didn't tell me the truth. The doctor told them (the children). They didn't tell me, not until we received a negative result from the tests. My children then told me the reasons why those tests such as a biopsy were needed. It was because my blood level (PSA index) increased too fast."

\subsection{Perceived seriousness of and susceptibility to cancer}

Almost one third of participants (12) believed that cancer was a very serious disease because when it was detected, it was usually at a late or advanced stage. Some participants believed that cancer could progress quickly and drastically without much warning. When patients found out that they had cancer, the disease had already progressed.

Cervical disease is complicated. Therefore, we need to get Pap smear. Without the screening, it will be too late when we find out and it will be life threatening... cancer is more serious than other diseases. Because if you have diabetes and you follow the doctor's advice "eat what you should eat, stay away from those kinds of food you shouldn't eat", then your condition can be stabilized. But cancer cannot be cured. (I8)

If you have other medical issues, it is not a problem as long as you receive proper treatment and know how to take care of it. But if one has cancer, it's difficult. Even the most advanced medical technology cannot buy more time for a few more years. Look at those celebrities who were fighting cancer. They were rich and had money but yet they still died of cancer. For this reason the stress of having cancer is high. (A5)

While many participants believed that cancer was a very serious problem and knew that many at their age had cancer, only one third of them felt that they were susceptible to having cancer. Many more female (11) than male participants (2) in this study believed they were. Inadequate knowledge of cancer might give these participants a false sense of security about their low susceptibility of cancer. For instance, a participant believed that since she attended screening examination regularly, she would be immune from cancer, "Because many people may have cancer at my age, I'm scared. But I don't think I'll have cancer because I attend screening examination and I'm healthy." Because of inadequate understanding on the causes of cancer, some participants, on the other hand, believed that they were totally vulnerable to developing cancer. One participant commented, "I think breast and cervical cancers are disorders of the hormonal system. Your blood type is related to these problems... I read that from some Japanese medical journals. They said if you have blood type B, you are more likely to have hormonal problems. I don't know the reasoning behind it because the article did not explain further on this. I found that more individuals with cervical tumor have blood type B... I consider myself high risk because I have blood type B."

Although many participants (12) learned that cancer was quite prevalent in the Chinese community, they did not know or were not sure why this was the case. One participant was very concerned about the fact that many people had cancer. She raised many questions about what caused cancer and what could be done to prevent it, "I'm not sure how cancer came about. I'd want to know what causes it so that I can prevent it. I'm not even sure why so many illnesses are cancer related. How come it's so easy to get cancer? Medical professionals tell you not to eat this or do that. But really, is it true that we can prevent it? ... I hope that it will not happen to me, but I just don't know why it happens. Sometimes we learn about cancer from the media or other sources. We learned 
that a lot of people have it. It's just hard to understand why".

Some male participants were confused about the difference between prostate related problems such as benign prostatic hypertrophy (prostate enlargement) and prostate cancer. They wondered whether an enlarged prostate would eventually turn to prostate cancer and asked what they could do to prevent or treat cancer. For instance, one participant had a long history of prostate enlargement and saw many doctors. He raised a lot of questions with his doctors about his prognosis and potential complications of prostate enlargement. He was very frustrated because his questions were not thoroughly answered:

I have prostate enlargement for more than 30 years. I saw many doctors in major hospitals in Nanjing and they all knew me. Doctors cannot tell me if my enlarged prostate will develop into cancer. What will be the symptoms? I do not have cancer now, but knowing how to prevent cancer is important. What should I do if I develop prostate cancer? I asked all these questions but so far I haven't got clear answers. Every doctor I saw recommended having the mass on my prostate removed. Will surgery guarantee that I will not have prostate cancer? (A6)

\subsection{Confusion, misconceptions, and holistic views about causes of cancer}

Medical professionals educate patients on common risk factors, such as genetics, family history, and poor diet that might lead to cancer. A few participants in this study recognized genetics and poor diet as risk factors for cancer and believed that cancer ran in the family. For instance, a participant believed that genetics played a role in cancer development, "I learned from newspapers and magazines that heredity is a contributing factor to prostate related problems. Since my father had prostate problems, I am especially concerned about myself and I am vigilant of my prostate problems. . . I think family genetics is a key factor. If your father had prostate cancer, you would be at a higher risk of having prostate cancer."

Although some participants suggested the role of genetics in the development of cancer, others were unsure that genetics played a role and attributed cancer to unfounded causes. For example, one participant believed that every person had both normal and cancer cells in the body; that when she became extremely tired and exhausted, she could get cancer easily because the normal cells in the body could not recognize or fight cancer cells, "Because when you get cancer, there is usually a genetic predisposition... You don't have to be scared because all of us live with cancer cells. When you are healthy, the normal cells can identify the cancer cells and overcome them... When you are extremely tired because of work or when your body is too exhausted, you may get cancer easily. Genetic factors are predisposing factors. Therefore, if you already have a family history of cancer but you still don't pay attention to your health, such as working too much and getting too tired, then you are prone to have cancer.' When participants were unclear about the cause of cancer, they speculated. For instance, a participant was puzzled as to what actually caused cancer, "Why does cancer happen? I'm always asking. Is it due to genetic factor? Is it because of poor hygiene? Is it due to poor diet or something else? I'm not sure. I am just guessing. Why some people have cancer and some do not?"

Many participants in this study had misconceptions, confusion, and incorrect assumptions about the causes of cancer. Common misconceptions about the causes of cancer included: excessive sexual activities, cancer being "contagious", excessive breast milk, women ignoring their reproductive or natural functions by using birth control or not breastfeeding their babies, having a certain blood type, and poor hygiene. Both male and female participants regarded excessive sexual activities as a contributing factor to cancer. For instance, a female participant believed that cervical cancer was caused by promiscuity and sexual indulgence, "Cervical cancer? Perhaps because they have been fooling around?" Another participant agreed, "Some people said it is because you have done something shameful, and then you became inflicted... which leads to cervical cancer." Male participants also attributed prostate cancer or prostate related symptoms to uncontrolled sexual urge and desires, too much sex, and sexual indulgence. This notion of "conserving energy" and "suppressing pleasure seeking desires", especially "sexual desires", as a way of preserving health is a hallmark of Taoist and Buddhist philosophies. ${ }^{[30,39]}$ A participant said, "Some said being sexually active, lack of control, or sexual indulgence make one prone to prostate cancer." Another commented, "Some may not care about having prostate enlargement. They must be very sexually active because they 'stimulate' their prostate a lot by engaging in sex too often." Cancer is believed to be contagious. Some participants attributed the causal factors of cancer with sexually transmitted diseases. One participant believed that physical contact during doctor's examination might spread cancer, "Another way is through physical contact, yes, when doctors are touching you during the examination. But talking about it won't spread cancer."

Some participants made up their own "theory" on the causes of cancer because they were confused about risk factors and causes of cancer. For example, one participant concluded that a woman whom she knew developed breast cancer shortly after she gave birth because she had "cold and excessive 
breast milk left in her breast". According to her "theory", the breast milk was "frozen to tiny particles" and became lumps in her breasts, which in turn caused her to develop breast cancer. This participant's theory reflected the Chinese belief of balancing "hot" and "cold" elements in one's body. ${ }^{[29]}$ Once this balance was upset, one was prone to illness.

When her baby drank too much breast milk while she had a cold, cancer developed in her breast but she did not know about it... I've got another friend who had too much breast milk and her baby couldn't finish it. She caught a bad cold and her breast milk was "frozen to tiny particles", forming a mass in her breast. After she migrated to the United Sates, she had a mastectomy. Nobody knew what she had. Some said it was breast cancer. Some said it was just a tumor... She said it was because she had "cold and excessive breast milk left in her breast" which became lumps. (I5)

The following two participants believed that women who did not breastfeed, or did not use their reproductive or "natural" functions, such as child bearing, were at a higher risk of having cancer. While there is some basis in medical literature regarding the association between breast cancer, child birth, and breastfeeding, the belief of these participants also reflected the Taoism value of health being a state of physical harmony with nature ${ }^{[29]}$ and that one should always act in accordance with nature and not against it.

As for breastfeeding, I have seen people who did not breastfeed and later developed breast cancer. They didn't use their body the way it was made for... This is a form of imbalance in the natural body function. When you upset the balance, the metabolism becomes abnormal. (C1)

In the old days, women had 8 children and their reproductive organs were used in the way "nature" made it for... women did not use birth control and therefore did not have cancer. Nowadays, women use various birth control methods, which conflict with the body system and its normal function. This will gradually lead to the development of diseases... women are not giving birth to babies enough or using their reproductive system frequently enough. (C3)

Some participants believed that blood type and poor hygiene were associated with the development of cancer. One participant said, "There are four different blood types in human beings. There are some blood types that cause people to get sick easily... Well, I read about this theory and I looked back at my family. Some of my family members have cancer. So, I thought it (cancer formation) is related to blood type because my younger sister and I do not have the same blood type. So, I think it depends not only on your own mental

Published by Sciedu Press well-being but also on your blood type.” A participant believed that poor immune system was a factor associated with cancer. He used an analogy of the Civil War in China to illustrate his argument, "Being weak in our body! Just like the Red Army in China, it depends on whether or not you have an adequate force of army. If the Red Amy had enough armed force to win the battle, it would not need to escape to 'Yin On' (a province in China to which the Republic of China retreated during the Civil War). Similarly this is how we get cancer. Yes, our immune system becomes weak and then you will get sick easily."

Traditional Chinese believed that the formation and progression of diseases are associated with social and environmental changes. Several participants in the study shared this holistic belief and stated that unhealthy cooking and poor eating habits might be a causal factor for cancer. As one participant put it, "There was a Chinese saying that fried food is no good (toxic) for our health. Therefore, if you don't control your diet and eat too much oily and fried food, you are not only more likely to have prostate cancer, but are also prone to have other medical problems." Chinese health beliefs and practices emphasize balance and harmony among human mind, body, and emotions with one's nature or environment. ${ }^{[28]}$ Mind and body are considered inseparable entities because they influence each other. Being emotionally imbalanced may put someone at a higher risk of developing diseases. For instance, one participant believed that being chronically unhappy, such as feeling depressed or anxious, would contribute to breast or cervical cancer, "I thought that you are more prone to having breast cancer if you are chronically unhappy, anxious or depressed... I just feel that when one is unhappy, it's easier to catch any illness. We don't know for sure how people get these diseases (cancer), but I think that they are somewhat related to our mental conditions. Our emotion does not just affect our chances of getting cancer but also many other diseases as well."

\section{DISCUSSION AND CONCLUSION}

Many studies on the topic of cancer among Asian Americans used quantitative research methodologies to explore factors such as socioeconomic status, information barriers, insurance status, and level of acculturation that may associate with cancer incidence and screening rates. ${ }^{[4,10,12,16,18]}$ Fewer studies used qualitative methodologies to learn about cancer screening experiences of Asian Americans. ${ }^{[15,17,22]}$ More studies were conducted with Asian American women to assess their level of adherence to cervical and breast cancer screening ${ }^{[11,16-18,20]}$ but very few were done on Chinese immigrant males. This qualitative study adds to the sparse literature by contributing to a better understanding on the cul- 
tural attitudes and beliefs toward the causes and prevention of cancer among medically underserved Chinese immigrant men and women in the metropolitan New Your city area. Guided by both the Explanatory Model Interview Catalogue and the Health Belief Model, this study explored the beliefs and perceptions of Chinese immigrant participants toward cancer, their perceived cause of cancer, their reaction to a cancer diagnosis, and their attitudes and experiences toward cancer screening. The findings of this study suggest that culture influences beliefs and attitudes toward cancer, as well as perceptions regarding the cause, susceptibility to, and seriousness of cancer.

Participants in this study reported both positive and negative attitudes toward cancer. Consistent with the study findings by Liang and colleagues, ${ }^{[22]}$ several participants expressed a sense of powerlessness toward cancer and were ready to accept their "fate". Traditional Chinese believe that the highest acceptance of God is to "listen to heaven and follow fate". [39] When unfortunate events happen, the individual should try his or her best, be positive, and leave the outcome to God. Cancer is often considered as a fatal disease which has no cure.

Contrary to the findings of Sadler et al. (1998)'s study, ${ }^{[40]}$ most of the participants in this study did not believe that thinking, talking, or learning about cancer could lead to bad luck or trigger the onset of cancer. In fact, several participants reported being calm when they first heard about cancer, because they believed that they had control on what they could do to deal with cancer and were psychologically prepared for it. This could be explained by the fact that participants in this study were recruited from the patient population of a community health center and those who attended cancer screening. The fact that they went for cancer screening in the first place reflected that they had overcome the taboo of cancer, and were willing and ready to deal with the possibility of a "positive" result. Therefore, receiving cancer screening can have the positive effect of helping the patient cope with the initial shock and anxiety related to the diagnosis of cancer. Attending cancer screening also empowers the patient by making him or her feel good about the decision of seeking screening before experiencing symptoms and giving them a sense of control by detecting the disease at an early stage. As a result, many participants believed that cancer screening was a preventive measure and considered it a priority in life.

Only a few participants in this study recognized the role of genetics and unhealthy diet as risk factors for cancer. Many held misconceptions, confusion, and incorrect assumptions about the causes of cancer. The "story" on the causes of cancer by these participants reflected traditional Chinese holistic belief of balancing "hot" and "cold" elements in one's body, and the Taoism value of health being a state of physical harmony with nature. ${ }^{[29]}$ These results were consistent with findings of several studies of Asian American groups. ${ }^{[15,22,41]}$ Breast cancer is considered a "contagious disease"[25,27] and developed because of "breast trauma" such as "pressure on the breasts" or the "use of wired bras". ${ }^{[15]}$ Ignorance and confusion on the risk factors and causes of cancer will put these individuals in a disadvantaged position because they do not know what to do to prevent or treat cancer. Therefore, it is important for health care providers to recognize that these specific cultural beliefs and practice of Chinese immigrants may influence their perceptions regarding the cause, susceptibility to, and seriousness of cancer.

The design and the implementation of the majority of cancer screening and education activities in the United States are based on self efficacy concepts of enhancing the patient's ability to control cancer by engaging in cancer screening activities. It is questionable whether this approach to cancer screening and education is optimal to working with Chinese immigrants who are seeking health care according to their specific cultural beliefs and personal practice. It is important for health care professionals to incorporate these specific health beliefs and practices of individuals into service delivery and patient education. Otherwise, they may misunderstand their patients, miss valuable diagnostic cues, and encounter higher rates of patient noncompliance with cancer screening guidelines. Studies show that culturally sensitive and language-appropriate educational interventions are likely to improve mammography adherence among Chinese American immigrant women. ${ }^{[42,43]}$

There are some limitations to this study. First of all, the sample size used in the study was modest. Second, participants were self-selected to participate in the study. Although participants came from diverse demographic backgrounds, this sample was non-representative as the sampling design was meant to capture the breadth of views and experiences of these participants rather than aiming at generalizing to the larger population of Chinese immigrants. Another limitation relates to the translation of Chinese words for which there is no true equivalence in English. The issue of translation raised validity concerns on the extent to which translated data accurately reflects the meaning and experience of participants. Despite its limitation, this study highlights the significance of cultural appropriateness and relevancy in the development and implementation of cancer promotion and cancer screening intervention for the Chinese immigrant population. Participants in this study already attended cancer screening activities and were better educated on cancer screening than those immigrants who were linguistically isolated and poorly 
educated. However, if some of these participants still had confusion and misconceptions about the causes of cancer and expressed negative attitude toward cancer and cancer screenings, one could only imagine tremendous amount of obstacles an average Chinese immigrant has to overcome to access quality cancer screening services. In conclusion, knowledge derived from this study is instrumental in raising awareness and broadening knowledge base among healthcare professionals who serve this client population. One could hope that a better understanding of the cultural attitudes and beliefs of this underserved population may help promote the concept of early detection and treatment of cancer for them

\section{REFERENCES}

[1] Miller BA, Chu KC, Hankey BF, et al. Cancer incidence and mortality patterns among specific Asian and Pacific Islander populations in the U.S. Cancer Causes Control. 2008 Apr; 19(3): 227-56.

[2] Chu KC, Chu KT. 1999-2001 Cancer mortality rates for Asian and Pacific Islander ethnic groups with comparisons to their 1988-1992 rates. Cancer. 2005 Dec 15; 104(12 Suppl): 2989-98. PMid:16270326.

[3] Gor B, Hoang TS, Yi J, et al. Cancer screening practices among Chinese and Vietnamese in the Greater Houston Area. Californian J Health Promot. 2007 May; 5: 105-112.

[4] McCracken M, Olsen M, Chen MS, et al. Cancer incidence, mortality, and associated risk factors among Asian Americans of Chinese, Filipino, Vietnamese, Korean, and Japanese ethnicities. CA Cancer J Clin. 2007 Jul-Aug; 57(4): 190-205.

[5] Lin SS, Clarke CA, Prehn AW, et al. Survival differences among Asian subpopulations in the United States after prostate, colorectal, breast, and cervical carcinomas. Cancer. 2002 Feb 15; 94(4): 1175-82. PMid:11920489. http://dx.doi.org/10.1002/cncr.10319

[6] American Cancer Society. New Screening Guidelines for Cervical Cancer, Atlanta, GA: American Cancer Society; 2012. Available from: http://www.cancer.org/cancer/news/new-scr eening-guidelines-for-cervical-cancer

[7] American Cancer Society. American Cancer Society recommendations for early breast cancer detection in women without breast symptoms, Atlanta. GA: American Cancer Society; 2015. http://www. cancer.org/cancer/breastcancer/moreinfor mation/breastcancerearlydetection/breast-cancer-e arly-detection-acs-recs

[8] American Cancer Society. American Cancer Society recommendations for prostate cancer early detection, Atlanta, GA: American Cancer Society; 2016. Available from: http://www. cancer.org/cancer/prostatecancer/mor einformation/prostatecancerearlydetection/prostate - cancer-early-detection-acs-recommendations

[9] Wolf AM, Wender RC, Etzioni RB, et al. American Cancer Society Guideline for the early detection of prostate cancer - Update 2010. CA Cancer J Clin. 2010 Mar-Apr; 60(2): 70-98.

[10] Ji CS, Chen MY, Sun J, et al. Cultural views, English proficiency and regular cervical cancer screening among older Chinese American women. Womens Health Issues. 2010 Jul-Aug; 20(4): 272-8.

[11] Lee-Lin F, Menon U, Pett M, et al. Breast cancer beliefs and mammography screening practice among Chinese American immigrants. J Obstet Gynecol Neonatal Nurs. 2007 May-Jun; 36(3): 212-21. as well as improve their access to cancer services.

\section{ACKNOWLEDGements}

The author whole heartedly thanks all study participants for their time and their openness in sharing their perspectives, personal experiences, as well as frustrations in accessing cancer screening and cancer education services. The author particularly wants to thank Elizabeth Luk, Stella GengSheng Lu, Amy Shek, Brenda Wan, and Junbo Yuan for their valuable support and help in completing this study.

\section{CONFLicts OF INTEREST Disclosure}

The authors have no potential conflicts of interest.
[12] Ma GX, Shive SE, Wang MQ, et al. Cancer screening behaviors and barriers in Asian Americans. Am J Health Behav. 2009 Nov-Dec; 33(6): 650-60

[13] Wang X, Fang C, Tan Y, et al. Evidence-based intervention to reduce access barriers to cervical cancer screening among underserved Chinese American women. J Womens Health. 2010 Mar; 19(3): 463-9.

[14] Asian American Federation Census Information Center. New 2010 census data show increasing diversity in New York City's Asian community. New York, NY: Asian American Federation; 2011. http://www. aafny.org/press/pressrelease.a sp?prid=126\&y=2011

[15] Ashing KT, Padilla G, Tejero J, et al. Understanding the breast cancer experience of Asian American women. Psychooncology. 2003 Jan-Feb; 12(1): 38-58.

[16] Juon HS, Kim M, Shankar S. Predictors of adherence to screening mammography among Korean American women. Prev Med. 2004 Sep; 39(3): 474-81. PMid:15313086. http://dx.doi.org/10.10 16/j.ypmed.2004.05.006s

[17] Lee-Lin F, Menon U, Nail L, et al. Findings from focus groups indicating what Chinese American immigrant women think about breast cancer and breast cancer screening. J Obstet Gynecol Neonatal Nurs. 2012 Apr 26.

[18] Taylor VM, Yasui Y, Burke N, et al. Pap testing adherence among Vietnamese American women. Cancer Epidemiol Biomarkers Prev. 2004 Apr; 13(4): 613-9.

[19] Sun A, Wong-Kim E, Stearman S. Quality of life in Chinese patients with breast cancer. Cancer. 2005 Dec 15; 104(12 Suppl): 2952-4. PMid:16270312.

[20] Lee-Lin F, Menon U, Pett M, et al. Measuring breast cancer and mammography screening beliefs among Chinese American immigrant women. West J Nurs Res. 2008 Nov; 30(7): 852-68.

[21] Lee-Lin F, Menon U, Nail L, et al. Findings from focus groups indicating what Chinese American immigrant women think about breast cancer and breast cancer screening. J Obstet Gynecol Neonatal Nurs. 2012 Apr 26.

[22] Liang W, Yuan E, Mandelblatt JS, et al. How do older Chinese women view health and cancer screening? Results from focus groups and implications for interventions. Ethn Health. 2004 Aug; 9(3): 283-304.

[23] Conde FA, Landier W, Ishida D, et al. Barriers and facilitators of prostate cancer screening among Filipino men in Haiwaii. Oncol Nurs Forum. 2011 Mar; 38(2): 227-33. 
[24] Tung WC. Prostate cancer screening among Asian American and Pacific Island men. Home Health Care Manage Pract. 2012 Feb; 24(1): 56-8. http://dx.doi.org/10.1177/1084822311422821

[25] Kwok C, Sullivan G. Chinese-Australian women's beliefs about cancer: implication for health promotion. Cancer Nurs. 2006 Sep-Oct; 29(5): E14-21. PMid:17006106. http://dx.doi.org/10.1097 /00002820-200609000-00014

[26] Wong-Kim E, Sun A, DeMattos MC. Assessing cancer beliefs in a Chinese immigrant community. Cancer Control. 2003 Sep-Oct; $10(5$ Suppl): 22-8.

[27] Wong-Kim E, Sun A, Merighi J. Understanding quality-of-life issues in Chinese women with breast cancer: a qualitative investigation. Cancer Control. 2005 Nov; 12 Suppl 2: 6-12.

[28] Tung WC. Cervical cancer screening among Hispanic and Asian American women and Pacific Island men. Home Health Care Manage Pract. 2011 Dec; 23(6): 480-3. http://dx.doi .org/10.1177 /1084822311413555

[29] Spector RE. Cultural diversity in health and illness (8th.). Prentice Hall; 2012.

[30] Ino SM, Glicken MD. Treating Asian American clients in crisis: a collectivist approach. Smith Coll Stud Soc. 1999 Jun; 69(3): 525-40. http://dx.doi.org/10.1080/00377319909517572

[31] Tu SP, Yasui Y, Kuniyuki AA, et al. Mammography screening among Chinese-American women. Cancer. 2003 Mar 1; 97(5): 1293-302.

[32] Corbin J, Strauss AL. Basics of qualitative research: techniques and procedures for developing grounded theory (4th ed.). Thousand Oaks: Sage Publications; 2014.

[33] Boyatzis RE. Transforming qualitative information: Thematic analysis and code development. Thousand Oaks: Sage Publications; 1998.

[34] Weiss M. Explanatory model interview catalogue (EMIC): framework for comparative study of illness. Transcult Psychiatry. 1997 Jun;
34(2): 235-63. http://dx.doi.org/10.1177/1363461597034 00204

[35] Champion VL, Skinner CS. The health belief model. In Glanz K, Rimer BK, Viswanath K, eds. Health behavior and health education: theory, research, and practice (4th ed). San Franscisco: Jossey-Bass, 2008. p. 45-65.

[36] Friese S. Qualitative data analysis with ATLAS.ti. (2nd ed.). Thousand Oaks: Sage Publications; 2014.

[37] Miles MB, Huberman AM, Saldana JN. Qualitative data analysis: A methods sourcebook. (3rd ed.). Thousand Oaks: Sage, 2014.

[38] Yin R. Case study research: design and methods. (2nded.). Thousand Oaks: Sage Publications; 2008.

[39] Chen YL. Conformity with nature: a theory of Chinese American elders' health promotion and illness prevention processes. ANS Adv Nurs Sci. 1996 Dec; 19(2): 17-26.

[40] Sadler GR, Nguyen F, Doan Q, et al. Strategies for reaching Asian Americans with health information. Am J Prev Med. 1998 Apr; 14(3): 224-228.

[41] Maxwell AE, Bastani R, Warda US. Demographic predictors of cancer screening among Filipino and Korean immigrants in the U.S. Am J Prev Med. 2000 Jan; 18(1): 62-8. http://dx.doi .org/10.10 16/S0749-3797(99)00110-5

[42] Liang W, Wang J, Chen MY, et al. Cultural views, language ability, and mammography use in Chinese American women. Health EducBehav. 2009 Dec; 36(6): 1012-25.

[43] Lim JW. Linguistic and ethnic disparities in breast and cervical cancer screening and health risk behaviors among Latina and Asian American women. J Womens Health. 2010 Jun; 19 (6): 1097107. PMid:20507210. http://dx.doi.org/10.1089/jwh. 2009. 1614 